\title{
Use of Xenon as Internal Standard for the Accurate Determination of Trace Elements in Water Samples by ICP-MS
}

\author{
V. Balaram*, M. Satyanarananan, D.V. Avdeeva, N. Berdnikov', Parijat Roy, S.S. Sawant, \\ K.S.V. Subramanyam, K.V. Anjaiah, C.T. Kamala, Ramavathi Mathur, and B. Dasaram \\ National Geophysical Research Institute, (Council of Scientific Industrial Research), \\ Hyderabad - 500007, India \\ ${ }^{a}$ Institute of Tectonics and Geophysics, FEB RAS, Khabarovsk, Russia
}

\section{INTRODUCTION}

Inductively coupled plasma mass spectrometry (ICP-MS) has become one of the most powerful analytical tools for the precise determination of trace elemental concentrations in a variety of geological and environmental materials, including ground and surface waters (1). Contamination of ground water due to natural and anthropogenic activities all over the world is seriously affecting the quality of ground and surface waters (2). Unfortunately, ever since the start of the industrial revolution, most of our ground and surface waters have been polluted (3-5). A major area of concern is the safety of public drinking water, and there has been growing concern about the concentrations of certain trace and ultra-trace elements in drinking water. Although at trace concentration levels some heavy metals (e.g., Fe and Zn) are essential for human health, most of them are toxic or poisonous even at low concentrations.

The toxic metals, such as As, Se, $\mathrm{Cd}, \mathrm{Cr}, \mathrm{Hg}, \mathrm{Pb}, \mathrm{Th}$, etc., enter the human body via the food chain, ambient air or drinking water, and often lead to health problems. Despite this growing concern, the efforts of most environmental scientists appear to be concentrated around a limited number of typical toxic trace elements (i.e., $\mathrm{Cr}, \mathrm{Cu}$, $\mathrm{Ni}, \mathrm{Cd}, \mathrm{As}, \mathrm{Hg}$, and $\mathrm{Pb}$ ), since most of them only have access to low

${ }^{*}$ Corresponding author.

E-mail: balaram1951@yaboo.com

\section{ABSTRACT}

Application of xenon $\left({ }^{129} \mathrm{Xe}\right)$ as an internal standard for the precise and accurate determination of several trace elements in different kinds of water samples by inductively coupled plasma mass spectrometry (ICP-MS) is described. The novelty of this approach is that no external addition of any reagent is involved since xenon is present as an impurity in the plasma gas itself. As a result, the possibility of introducing any type of elemental impurities through the addition of an internal standard will be completely avoided. Therefore, this feature will be of great value when determinations are carried out for elements present at $\mathrm{ng} / \mathrm{mL}$ and sub-ng/mL levels.

The utility of ${ }^{129} \mathrm{Xe}$ as an internal standard has been validated using standard reference materials NIST 1640d, NIST 1643e, and NIST 1640a. The accuracies and precisions achieved were markedly better when internal standardization was applied. In general, trace element data in a variety of water samples were obtained with $<5 \%$ RSD with comparable accuracy in each case, suggesting that this method can be applied routinely for the determination of trace elements in water.

sensitivity techniques such as flame atomic absorption spectrometry (FAAS) and inductively coupled plasma atomic emission spectrometry (ICP-AES). These techniques cannot determine most of the sig- nificant elements in different environmental matrices on a routine basis. However, due to advances in analytical instrumentation, and especially with the advent of inductively coupled plasma mass spectrometry (ICP-MS), several studies are currently in progress to understand the toxicological effects of elements like Pt, Pd, and Rh (6). There is a need for routine monitoring of ambient waters to allow us to establish an accurate database of inorganic constituents in order to identify and follow the trends of possible pollution of the environment, and to understand the results for any required ecological redemption activities. Trace element concentrations are also required in other applied studies, such as hydrogeochemical prospecting. Hence, there is a great need to develop analytical protocols suitable for the precise and accurate determination of all suspected inorganic elements in different kinds of water samples. Such studies depend on the ability to perform rapid and precise measurements of different trace elements at the $\mathrm{ng} / \mathrm{mL}$ and $\mathrm{pg} / \mathrm{mL}$ levels. This requires highly sensitive analytical techniques such as inductively coupled plasma mass spectrometry (ICP-MS) (7).

Because of its detection power, multi-element isotopic capability, and dynamic linear range, ICP-MS is ideally suited for the analysis of different types of water samples. Several papers have been published on the determination of trace elements in water by ICP-MS (1, 8 and refer- 
ences therein). Major sources of errors that limit precision and accuracy are dynamic range, drift, and matrix effects (9). The linear dynamic range is limited by the hardware of the instrument and can be improved by dead time correction (10). In general, ICP-MS measurements are affected by instrumental drift caused by fluctuations in the electronics and also by fluctuations in the plasma due to variations in the chemical composition of the sample solutions, which affect the precision and accuracy of the measurements. External and internal standards are used to improve precision and accuracy. Internal standardization is a critical step in the sample preparation procedure, particularly when an internal standard element (i.e., In, Rh, etc.) has to be added externally. This will severely affect the accuracy if the element added is accompanied by impurities, even at trace concentration levels, and particularly so when the elements have to be determined at extremely low concentration levels. Any contami- nation in the externally added internal standard would contribute to errors, apart from the usual errors which cannot be avoided during the course of analysis. Ideally, internal standards should be noninterfered and mono-isotopic. Commonly used internal standards include ${ }^{9} \mathrm{Be},{ }^{45} \mathrm{Sc},{ }^{89} \mathrm{Y},{ }^{103} \mathrm{Rh},{ }^{115} \mathrm{In}$, and ${ }^{209} \mathrm{Bi}(11,12)$. Under normal conditions, the internal standard element chosen should not be present in the sample and should be added to all blanks, standards, and samples in equal concentrations (typically 10-20 ng/mL).

The principal objective of the present study was to develop an analytical procedure for the accurate determination of a number of trace elements in ground and surface water samples by using ${ }^{129} \mathrm{Xe}$ as the internal standard for a routine application. An isotope of xenon, which is present as an impurity in the plasma gas (argon), has been utilized successfully as an internal standard for obtaining extremely accurate and precise data, which is shown in this work.

TABLE I

Instrumental and Data Acquisition Parameters of the ICP-MS Instrument

\begin{tabular}{lr}
\hline RF Power & $1100 \mathrm{~W}$ \\
Argon gas flow: & \\
$\quad$ Nebulizer & $0.70 \mathrm{~L} / \mathrm{min}$ \\
$\quad$ Auxillary & $1.20 \mathrm{~L} / \mathrm{min}$ \\
$\quad$ Plasma & $15 \mathrm{~L} / \mathrm{min}$ \\
Lens voltage & 5.00 \\
Sample uptake rate & $0.80 \mathrm{~mL} / \mathrm{min}$ \\
Data acquisition & Quantitative \\
\hline Parameters & Mode \\
Measuring mode & 1 \\
Point per peak & 50 \\
Number of sweeps & 50 \\
Dwell time (microseconds) & 2500 \\
Integration time (ms) & 3 \\
Replicates & $129 \mathrm{Xe}$ \\
Internal standard & \\
\hline
\end{tabular}
Levels of Impurities $(\mu \mathrm{g} / \mathrm{g})$ in Different Grades of Argon ${ }^{\mathrm{a}}$

\begin{tabular}{lcccc}
\hline Impurity & $\begin{array}{c}\text { XL Argon } \\
(99.0003 \%)\end{array}$ & $\begin{array}{c}\text { Argon } \\
\text { Iolar I }\end{array}$ & $\begin{array}{c}\text { Argon } \\
\text { Iolar II }\end{array}$ & $\begin{array}{c}\text { Argon } \\
\text { Standard }\end{array}$ \\
\hline $\mathrm{O}_{2}$ & 1.5 & 2 & 4 & 5 \\
$\mathrm{H}_{2} \mathrm{O}$ & 1 & 2 & 4 & 5 \\
$\begin{array}{l}\text { Total Hydro- } \\
\text { carbon (THC) }\end{array}$ & 0.2 & 0.2 & 0.5 & 0.5 \\
$\mathrm{CO}$ & 0.2 & $\mathrm{a}$ & 0.5 & 0.5 \\
$\mathrm{CO}$ & 0.5 & $\mathrm{a}$ & 0.5 & 0.5 \\
$\mathrm{~N}_{2}$ & 2 & 3 & 10 & 20 \\
$\mathrm{H}_{2}$ & $\mathrm{a}$ & $\mathrm{a}$ & 2 & 2 \\
$\mathrm{~N}_{2} \mathrm{O}$ & & & 0.5 & 1 \\
\hline
\end{tabular}

${ }^{a}$ From BOC India, Ltd., Hyderabad: Data for welding grade argon is not available.

\section{EXPERIMENTAL}

\section{Instrumentation, Reagents, and Materials}

A PerkinElmer ${ }^{\circledR}$ Model ELAN® ${ }^{\circledR}$ DRCTM II ICP mass spectrometer (PerkinElmer, Inc., Shelton, CT, USA) was used throughout. The sample introduction consisted of a standard Meinhard ${ }^{\circledR}$ nebulizer with a cyclonic spray chamber. All quantitative measurements were performed using the instrument software (ELAN v. 3.1). This software uses knowledge-driven routines in combination with numerical calculations (quantitative analysis) to perform an automated interpretation of the spectrum of interest. Several well-known isobaric interferences are programmed and the corrections are automatically applied (7). The same instrument is also being used at the collaborating laboratory of the Institute of Tectonics and Geophysics, Khabarovsk, Russia. The instrumental and data acquisition parameters are listed in Table I.

The gaseous impurity levels of different grades of argon gases (from BOC India Ltd., Hyderabad, India) are listed in Table II. Unfortunately, the data on xenon levels in 


\section{A Amic $_{\text {Soectroscopy }}^{\text {tom }}$}

different grades of argon are not available from the manufacturer. Our study indicated that the welding grade argon and the standard argon contained more xenon as impurity.

Trace elements in water reference materials NIST 1643d, NIST $1643 \mathrm{e}$, and NIST 1640a were obtained from the National Institute of Standards and Technology, Gaithersburg, MD, USA. Milli-Q ${ }^{\mathrm{TM}}$ water $\left(18 \mathrm{M} \Omega\right.$ ) (Millipore ${ }^{\circledR}$ Corporation, USA) and nitric acid (Suprapur ${ }^{\circledR}$, E. Merck, Darmstadt, Germany) were used for all of the investigations.

\section{RESULTS AND DISCUSSION}

The maximum tolerable contamination levels (Table III) for many elements in drinking water have been legislated by various national and international environmental protection agencies (13). However, many other elements, which were not commonly used in the past, e.g., rare earth elements (REEs) and platinum group elements (PGEs), are increasingly being used in modern industries for the production of numerous new materials, finished products, and other technological applications. These elements are finding their way into many environmental pathways and could also contribute to environmental pollution, especially to ground and surface waters. As a consequence, a fourth group of elements, namely REEs and PGEs, have been added to the already existing classification (14) (see Figure 1). This group represents important elements found in the environment and need to be studied to understand the various aspects of human health. Any analytical methodology developed should also be applicable to the precise determination of these elements.
TABLE III

Acceptable Concentration Levels $(\mu \mathrm{g} / \mathrm{mL})$ of Trace Elements in Drinking Water (13)

\begin{tabular}{|c|c|c|c|c|c|}
\hline Element & Indian $^{\mathrm{a}}$ & $\mathrm{WHO}^{\mathrm{b}}$ & $\mathrm{UK}^{\mathrm{c}}$ & US EPA $^{\mathrm{d}}$ & $\mathrm{EEC}^{\mathrm{e}}$ \\
\hline $\mathrm{Al}$ & - & - & 0.2 & - & 0.2 \\
\hline Ag & - & - & 0.01 & 0.05 & 0.01 \\
\hline As & 0.05 & 0.01 & 0.05 & 0.05 & 0.05 \\
\hline B & - & - & 2 & - & - \\
\hline $\mathrm{Ba}$ & - & - & 1 & 1 & 1 \\
\hline $\mathrm{Be}$ & & - & - & 0.001 & - \\
\hline $\mathrm{Ca}$ & 75 & - & 250 & - & - \\
\hline $\mathrm{Cd}$ & 0.01 & 0.003 & 0.005 & 0.01 & 0.005 \\
\hline $\mathrm{Cl}^{-}$ & 250 & 250 & 400 & - & - \\
\hline $\mathrm{CN}^{-}$ & 0.05 & - & 0.05 & - & - \\
\hline $\mathrm{Cr}$ & 0.05 & 0.05 & 0.05 & 0.05 & 0.05 \\
\hline $\mathrm{Cu}$ & 0.05 & 1 & 3 & 1 & - \\
\hline $\mathrm{F}^{-}$ & $0.6-1.2$ & 1.5 & 1.5 & - & - \\
\hline $\mathrm{Fe}$ & 0.3 & 0.3 & 0.2 & 0.3 & 0.2 \\
\hline $\mathrm{Hg}$ & 0.001 & 0.001 & 0.001 & - & - \\
\hline $\mathrm{K}$ & - & - & 12 & - & - \\
\hline $\mathrm{Mg}$ & 30 & - & 50 & - & - \\
\hline $\mathrm{Mn}$ & 0.1 & 0.05 & 0.05 & 0.1 & 0.05 \\
\hline $\mathrm{Na}$ & - & - & 150 & - & - \\
\hline $\mathrm{Ni}$ & - & - & 0.05 & 0.05 & 0.05 \\
\hline $\mathrm{NO}_{3}{ }^{2-}$ & 45 & 50 & 50 & - & - \\
\hline $\mathrm{NO}_{2}$ & - & - & 0.01 & - & - \\
\hline $\mathrm{P}$ & - & - & 2.2 & - & - \\
\hline $\mathrm{Pb}$ & 0.1 & 0.01 & 0.05 & 0.05 & 0.05 \\
\hline $\mathrm{Sb}$ & - & - & 0.01 & - & 0.01 \\
\hline $\mathrm{Se}$ & 0.01 & 0.01 & 0.01 & 0.01 & 0.01 \\
\hline $\mathrm{SO}_{4}$ & 150 & 250 & 250 & - & - \\
\hline $\mathrm{Zn}$ & 5 & 3 & 5 & 5 & 5 \\
\hline
\end{tabular}

${ }^{\text {a } I S ~ S p e c .10500 ~(1991) . ~}$

b WHO Spec. (1997).

${ }^{\mathrm{c}}$ Environment \& Science Directorate Water Quality and Laboratories Group, U.K. (1993).

${ }^{\mathrm{d}}$ EEC $=$ European Economic Community, Nham TT (1995).

${ }^{\mathrm{e}} \mathrm{WHO}=$ World Health Organization.

Fig. 1. Trace Elements in the Environment (modified, Ref. 14).

\begin{tabular}{|c|c|}
\hline $\begin{array}{l}\text { The first group is toxic at all con- } \\
\text { centrations and has no known bio- } \\
\text { logical functions: } \\
\text { i.e., } \mathrm{Cd}, \mathrm{Hg}, \mathrm{Pb} \text {, etc. }\end{array}$ & $\begin{array}{l}\text { The second group is less toxic; } \\
\text { however, still toxic if present in } \\
\text { more than the permitted concentra- } \\
\text { tions and known to have no biologi- } \\
\text { cal functions: } \\
\text { i.e., As, Sb, Bi, In, Th, etc. }\end{array}$ \\
\hline $\begin{array}{l}\text { The third group includes essen- } \\
\text { tial metal/metalloids which are } \\
\text { required for various biochemical } \\
\text { and physiological processes and are } \\
\text { toxic above certain concentration } \\
\text { levels: } \\
\text { i.e., } \mathrm{Cu}, \mathrm{Co}, \mathrm{Fe}, \mathrm{Se}, \mathrm{Zn} \text {, etc. }\end{array}$ & $\begin{array}{l}\text { The fourth group includes metals } \\
\text { that are potentially toxic even at } \\
\text { very low concentration levels and } \\
\text { for which not much information is } \\
\text { available: } \\
\text { i.e., PGEs, REEs, and other } \\
\text { elements. }\end{array}$ \\
\hline
\end{tabular}


The behavior of elements in the Ar plasma is largely dependent on physical properties such as atomic mass, ionization potential, concomitant elements, and the temperature of the plasma. In order to effectively correct for temporal variations in signal intensity (largely dependent on the variations in the physical behavior of the analyte in the plasma), the physical properties of the internal standard must be carefully matched to those of the isotopes of interest in the analytical program. For example, ${ }^{103} \mathrm{Rh}$ may be appropriate for ${ }^{85} \mathrm{Rb},{ }^{88} \mathrm{Sr}$, and ${ }^{89} \mathrm{Y}$, but ${ }^{209} \mathrm{Bi}$ may work better for ${ }^{208} \mathrm{~Pb},{ }^{232} \mathrm{Th}$, and ${ }^{238} \mathrm{U}$. In our studies related to the determination of trace elements (including REEs and PGEs) in geological samples, ${ }^{103} \mathrm{Rh}$, ${ }^{111} \mathrm{Cd},{ }^{115} \mathrm{In},{ }^{205} \mathrm{Tl},{ }^{209} \mathrm{Bi}$, etc., have been successfully used $(7,11,15)$. However, when external additions are involved, there exists the possibility of contamination and considerable error in the analysis, especially when the analytes are present at very low concentrations. In view of this, the use of xenon as an internal standard, which is already present as an impurity in the plasma gas (argon) itself, has been attempted. This is of definite advantage since there is no need for external additions and thus minimizes external contamination. The concentration of xenon (as an impurity) in any given argon cylinder is found to be always constant throughout the use of the cylinder.

Xenon has nine stable isotopes: ${ }^{124} \mathrm{Xe}(0.096 \%),{ }^{126} \mathrm{Xe}(0.090 \%)$, ${ }^{128} \mathrm{Xe}(1.919 \%),{ }^{129} \mathrm{Xe}(26.44 \%)$, ${ }^{130} \mathrm{Xe}(4.08 \%),{ }^{131} \mathrm{Xe}(21.18 \%)$, ${ }^{132} \mathrm{Xe}(26.89 \%),{ }^{134} \mathrm{Xe}(10.44 \%)$, ${ }^{136} \mathrm{Xe}(8.87 \%)$. Since the first ionization potential of xenon is less than that of the plasma gas (argon), availability of a sufficient number of singly charged ions is not a problem. Table IV lists the number of isotopes of xenon, and the polyatomic and isobaric interferences, which can be encountered during ICP-MS analysis. The ${ }^{129} \mathrm{Xe}$ isotope has been used in all of these investigations, since it has about 26\% natural abundance and no isobaric overlaps. The instrument was optimized using a solution containing ${ }^{24} \mathrm{Mg},{ }^{59} \mathrm{Co},{ }^{115} \mathrm{In}$, and ${ }^{238} \mathrm{U}$ at $1 \mathrm{ng} / \mathrm{mL}$. For best performance of the instrument, the nebulizer gas flow rate of $0.7 \mathrm{~L} / \mathrm{min}$ was found to be optimum. The oxide levels were $<2.5 \%$ with respect to Ce and about 35,000 counts for ${ }^{115} \mathrm{In}$ (1 ng/mL).

A $10 \mathrm{ng} / \mathrm{mL}$ synthetic standard solution was utilized for calibration to analyze the water samples collected from ponds near Khabarovsk, Far East Russia. A 20 ng/mL synthetic standard solution was also analyzed for $\mathrm{Cr}, \mathrm{Mn}, \mathrm{Fe}, \mathrm{Co}, \mathrm{Ni}, \mathrm{Cu}$, $\mathrm{Zn}, \mathrm{Cd}, \mathrm{Sn}, \mathrm{Sb}$, and $\mathrm{Pb}$ to check the accuracy of the data. The results obtained with and without the use of ${ }^{129} \mathrm{Xe}$ as internal standard are listed in Table V. The argon gas supplied in Khabarovsk, Russia, had a considerable amount of xenon as impurity which was highly useful since about 25,000 counts were obtained for ${ }^{129} \mathrm{Xe}$. At this concentration level of xenon, it works as a perfect internal standard. These results indicate that the precisions are much better when internal standardization was applied. The abnormalities noticed in the case of Fe and $\mathrm{Sn}$ cannot be explained with the available data. In another experiment, after calibrating the instrument with NIST 1643d and NIST 1643e, excellent data (except Si) was generated on NIST 1640a and the results are listed in Table VI. In general, silica is known to suffer from background and numerous other interferences. The results presented here show precisions better than $4 \%$ RSD in most cases and demonstrate the utility of ${ }^{129} \mathrm{Xe}$ as an internal standard.

As part of the hydrogeochemical prospecting studies for the determination of PGEs in the Madawara igneous complex (Lalitpur District of Uttar Pradesh, northern part of India), several ground and surface water samples were analyzed. Many trace elements and PGEs (Tables VII and VIII) were determined by ICP-MS using xenon as the internal standard. The PGEs were separated by using an ion exchange procedure described by Kamala et al. (2012) (16) before ICP-MS analysis. Since PGE determinations suffer from numerous spectroscopic and non-spectroscopic

\section{TABLE IV}

Various Isotopes of Xenon, Their Abundances and Possible Interferences of Polyatomic Ions in ICP-MS Measurements

\begin{tabular}{|c|c|c|c|}
\hline Isotope & Abundance & $\begin{array}{l}\text { Interferences } \\
\text { (May and Wiedmeyer, } \\
\text { 1998, Ref. 18) }\end{array}$ & Remarks \\
\hline${ }^{124} \mathrm{Xe}$ & $(0.096 \%)$ & ${ }^{124} \mathrm{Te},{ }^{108} \mathrm{Pd}^{16} \mathrm{O}^{+}$ & \\
\hline${ }^{126} \mathrm{Xe}$ & $(0.090 \%)$ & ${ }^{126} \mathrm{Te},{ }^{110} \mathrm{Pd}^{16} \mathrm{O}^{+}$ & \\
\hline${ }^{128} \mathrm{Xe}$ & (1.919\%) & ${ }^{128} \mathrm{Te},{ }^{96} \mathrm{Ru}^{16} \mathrm{O}^{+}{ }_{2}$ & \\
\hline${ }^{129} \mathrm{Xe}$ & $(26.44 \%)$ & ${ }^{113} \mathrm{Cd}^{16} \mathrm{O},{ }^{113} \operatorname{In}^{16} \mathrm{O}$ & $\begin{array}{l}\text { Most ideally suited, } \\
\text { No isobaric overlap }\end{array}$ \\
\hline${ }^{130} \mathrm{Xe}$ & $(4.08 \%)$ & ${ }^{130} \mathrm{Te},{ }^{98} \mathrm{Ru}^{16} \mathrm{O}^{+}{ }_{2}$ & \\
\hline${ }^{131} \mathrm{Xe}$ & $(21.18 \%)$ & ${ }^{115} \mathrm{Sn}^{16} \mathrm{O}$ & $\begin{array}{l}\text { Next most ideally suited, } \\
\text { No isobaric overlap }\end{array}$ \\
\hline${ }^{132} \mathrm{Xe}$ & $(26.89 \%)$ & ${ }^{116} \mathrm{Sn} 1^{6} \mathrm{O},{ }^{132} \mathrm{Ba}$ & \\
\hline${ }^{134} \mathrm{Xe}$ & $(10.44 \%)$ & ${ }^{1186} \mathrm{Sn}^{16} \mathrm{O},{ }^{134} \mathrm{Ba}$ & \\
\hline${ }^{136} \mathrm{Xe}$ & $(8.87 \%)$ & ${ }^{120} \mathrm{Sn}^{16} \mathrm{O},{ }^{136} \mathrm{Ba}$ & \\
\hline
\end{tabular}




\section{Atomic Spectroscopy \\ 1 Vol. 33(2), March/April 2012}

TABLE V

Concentrations of Some Trace Elements in Ground Water Samples and Synthetic Standard Solution With and Without (W/O) Internal Standardization (IS)

\begin{tabular}{|c|c|c|c|c|c|c|c|c|c|}
\hline \multicolumn{2}{|c|}{ Ana-Mass } & \multicolumn{2}{|c|}{$20 \mathrm{ng} / \mathrm{mL}$} & \multicolumn{2}{|c|}{$\mathrm{W}-01^{\mathrm{a}}$} & \multicolumn{2}{|c|}{$\mathrm{W}-04^{\mathrm{a}}$} & \multicolumn{2}{|c|}{$\mathrm{W}-07^{\mathrm{a}}$} \\
\hline lyte & No. & With IS & W/O IS & With IS & W/O IS & With IS & W/O IS & With IS & W/O IS \\
\hline $\mathrm{Cr}$ & 53 & $19.98 \pm 0.99$ & $19.14 \pm 1.72$ & $1.990 \pm 0.100$ & $2.350 \pm 0.210$ & $1.920 \pm 0.095$ & $2.223 \pm 0.202$ & $1.259 \pm 0.062$ & $1.259 \pm 0.113$ \\
\hline $\mathrm{Mn}$ & 55 & $19.98 \pm 0.79$ & $19.40 \pm 1.94$ & $67.87 \pm 2.710$ & $68.46 \pm 6.850$ & $61.90 \pm 2.475$ & $60.92 \pm 6.099$ & $62.11 \pm 2.483$ & $62.07 \pm 5.298$ \\
\hline $\mathrm{Fe}$ & 57 & $19.71 \pm 0.98$ & $12.22 \pm 1.21$ & $1119.6 \pm 50.98$ & $317.9 \pm 29.01$ & $1190.2 \pm 58.5$ & $329.2 \pm 29.66$ & $444.3 \pm 22.216$ & $421.1 \pm 36.90$ \\
\hline Co & 59 & $20.06 \pm 1.00$ & $19.89 \pm 1.90$ & $0.558 \pm 0.027$ & $0.586 \pm 0.053$ & $0.552 \pm 0.027$ & $0.566 \pm 0.058$ & $0.437 \pm 0.021$ & $0.444 \pm 0.040$ \\
\hline $\mathrm{Ni}$ & 60 & $20.01 \pm 1.01$ & $19.59 \pm 1.99$ & $1.760 \pm 0.090$ & $1.854 \pm 0.185$ & $1.977 \pm 0.098$ & $2.021 \pm 0.205$ & $1.858 \pm 0.093$ & $1.868 \pm 0.189$ \\
\hline $\mathrm{Cu}$ & 63 & $20.07 \pm 1.00$ & $19.64 \pm 1.77$ & $2.440 \pm 0.120$ & $2.750 \pm 0.250$ & $10.89 \pm 0.540$ & $10.97 \pm 0.989$ & $3.243 \pm 0.161$ & $3.298 \pm 0.297$ \\
\hline $\mathrm{Zn}$ & 68 & $20.04 \pm 1.01$ & $18.17 \pm 1.64$ & $9.650 \pm 0.480$ & $9.980 \pm 0.900$ & $19.28 \pm 0.980$ & $17.85 \pm 1.608$ & $7.868 \pm 0.392$ & $7.952 \pm 0.716$ \\
\hline $\mathrm{Cd}$ & 114 & $20.07 \pm 0.90$ & $19.92 \pm 2.00$ & $0.070 \pm 0.002$ & $0.076 \pm 0.009$ & $0.021 \pm 0.001$ & $0.025 \pm 0.004$ & $0.039 \pm 0.002$ & $0.039 \pm 0.004$ \\
\hline Sn & 120 & $20.06 \pm 1.01$ & $19.53 \pm 1.73$ & $0.363 \pm 0.018$ & $0.711 \pm 0.065$ & $0.103 \pm 0.004$ & $0.440 \pm 0.041$ & $0.259 \pm 0.012$ & $0.263 \pm 0.024$ \\
\hline $\mathrm{Sb}$ & 121 & $19.98 \pm 0.75$ & $9.51 \pm 1.760$ & $0.091 \pm 0.004$ & $0.098 \pm 0.010$ & $0.093 \pm 0.003$ & $0.097 \pm 0.009$ & $0.087 \pm 0.003$ & $0.087 \pm 0.008$ \\
\hline $\mathrm{Pb}$ & 208 & $20.05 \pm 1.01$ & $19.79 \pm 1.78$ & $1.310 \pm 0.070$ & $1.40 \pm 0.1270$ & $2.58 \pm 0.1270$ & $2.632 \pm 0.237$ & $1.038 \pm 0.052$ & $1.052 \pm 0.095$ \\
\hline $\begin{array}{l}\mathrm{Xe} \\
\text { (Inter }\end{array}$ & $\begin{array}{l}129 \\
\text { sity) }\end{array}$ & 24459 & & 24979 & & 24672 & & 24791 & \\
\hline
\end{tabular}

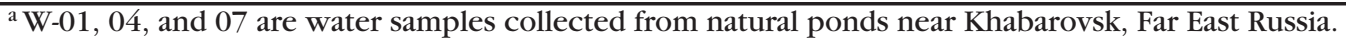

TABLE VI

Trace Element Data for NIST 1640a Water With and Without Internal Standard by ICP-MS in Comparison With Certified Values

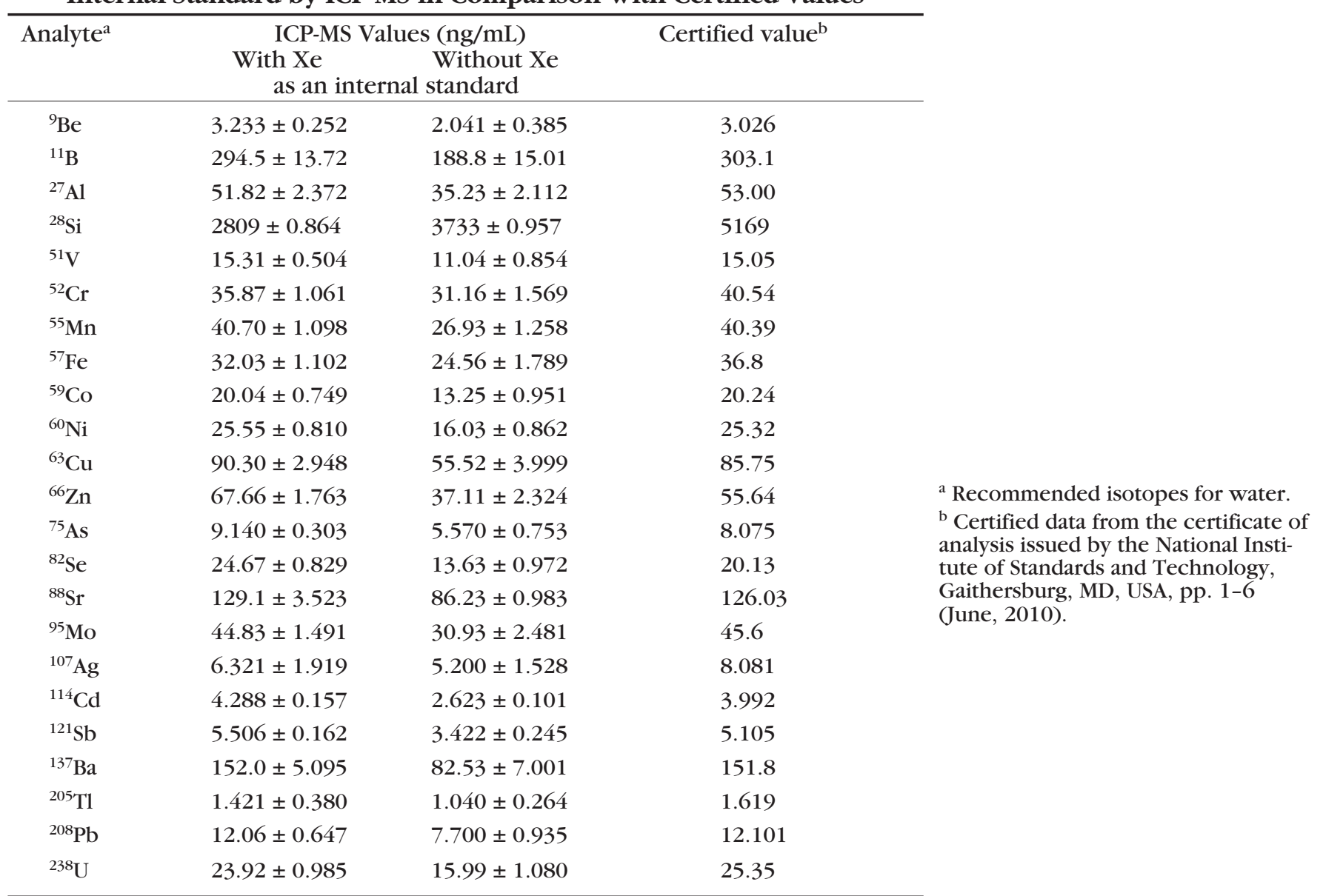


TABLE VII

Analytical Data for the Determination of PGEs ( $\mathrm{ng} / \mathrm{mL}$ ) in Surface and Ground Water Samples

(From Madawara Igneous Complex, Uttar Pradesh, India) by ICP-MS With ${ }^{129} \mathrm{Xe}$ as Internal Standard

\begin{tabular}{ccccccc}
\hline Sample & ${ }^{101} \mathrm{Ru}$ & ${ }^{103} \mathrm{Rh}$ & ${ }^{105} \mathrm{Pd}$ & ${ }^{191} \mathrm{Ir}$ & ${ }^{195} \mathrm{Pt}$ & ${ }^{197} \mathrm{Au}$ \\
\hline M1 & 0.004 & 0.008 & 0.212 & 0.004 & 0.008 & 0.281 \\
M2 & 0.006 & 0.009 & 0.151 & 0.006 & 0.009 & 0.148 \\
M3 & 0.017 & 0.044 & 0.032 & 0.001 & 0.004 & 0.054 \\
M4 & 0.005 & 0.021 & 0.030 & 0.001 & 0.009 & 0.049 \\
M5 & 0.006 & 0.011 & 0.118 & 0.002 & 0.007 & 0.083 \\
M6 & 0.005 & 0.016 & 0.032 & 0.001 & 0.004 & 0.047 \\
M7 & 0.003 & 0.009 & 0.070 & 0.002 & 0.005 & 0.069 \\
M8 & 0.001 & 0.006 & 0.079 & 0.002 & 0.004 & 0.053 \\
M9 & 0.002 & 0.008 & 0.062 & 0.003 & 0.005 & 0.040 \\
M10 & 0.003 & 0.004 & 0.057 & 0.002 & 0.003 & 0.032 \\
M11 & 0.002 & 0.003 & 0.054 & 0.001 & 0.004 & 0.029 \\
M12 & 0.005 & 0.016 & 0.028 & bdl $^{\mathrm{a}}$ & 0.008 & 0.022 \\
M13 & 0.003 & 0.003 & 0.055 & 0.001 & 0.004 & 0.025 \\
M14 & 0.002 & 0.005 & 0.057 & 0.002 & 0.003 & 0.022 \\
M15 & 0.003 & 0.003 & 0.051 & 0.001 & 0.004 & 0.026 \\
M16 & 0.003 & 0.002 & 0.052 & 0.002 & 0.003 & 0.021 \\
M17 & 0.008 & 0.015 & 0.008 & 0.001 & 0.003 & 0.020 \\
M18 & 0.003 & 0.003 & 0.053 & bdl $^{\mathrm{a}}$ & 0.002 & 0.021 \\
M19 & 0.002 & 0.007 & 0.053 & 0.001 & 0.003 & 0.019 \\
M20 & 0.005 & 0.012 & 0.023 & bdl $^{\mathrm{a}}$ & 0.003 & 0.014 \\
\hline
\end{tabular}

${ }^{\mathrm{a}} \mathrm{bdl}=$ below detection limits.

interferences (17), ion exchange separation was attempted to separate the PGEs from rock matrices before their determination. A multielement synthetic standard solution (Inorganic Ventures, USA) at a concentration of $1 \mathrm{ng} / \mathrm{mL}$ was used for calibration. Since PGEs are not present in the NIST calibration standards, synthetic multi-element standards were used for calibration. The recovery studies (Table IX) showed that the results are reasonably accurate and can be used for interpretation. All other trace elements were determined after directly diluting the solution 20 times with Milli-Q ${ }^{\mathrm{TM}}$ water (because of the very high total dissolved solids) without adopting a separation or pre-concentration procedure.
In all of these investigations, consistent results were obtained for the trace elements, including the PGEs.

The PGE results in the ground and surface water samples from the Madawara igneous complex (Table VIII) show anomalous concentrations for $\mathrm{Pd}$ and $\mathrm{Au}$, indicating the presence of mineralized zones in the area. More studies are required for locating the mineralized zones.

\section{CONCLUSION}

This work successfully demonstrated the use of xenon $\left({ }^{129} \mathrm{Xe}\right)$ as an internal standard for the determination of trace elements and PGEs in a various ground and surface water samples. Very good agreement between measured and certi- fied values was achieved for the majority of the elements where values were available for comparison. The results obtained for the NIST 1640a reference material show that the method can be utilized for monitoring the concentrations of various toxic elements in drinking water. This is a simple method, does not involve any addition of reagents, and avoids associated contamination problems.

\section{ACKNOWLEDGMENTS}

The authors thank Prof. Mrinal K. Sen, Director, National Geophysical Research Institute, Hyderabad, India, and the Director of the Institute of Tectonics and Geophysics, FEB RAS, Khabarovsk, Russia, for giving permission to publish this work.

Received October 19, 2011.

\section{REFERENCES}

1. V. Balaram, At. Spectrosc. 14, No.6, 174 (1993).

2. S.D. Richardson and T.A. Ternes, Anal. Chem. 77, 3807 (2005).

3. K. Chandrasekhar, N.S. Chary, C.T. Kamala, J.V. Rao, V. Balaram and Y. Anjaneyulu, Environ. International 29, 601 (2003).

4. M. Satyanarayanan, V. Balaram, Md.S.A. Hussin, M.A.R.A. Jemaili, T.G. Rao, R. Mathur, B. Dasaram, S.L. Ramesh, Environ. Monit. Assess. 131, 117 (2007).

5. M.V. Reddy, K.S. Babu, V. Balaram and M. Satyanarayanan M, Environ. Monit. Assess., DOI 10. 1007 10661-011-2094-7 (2011).

6. R. Mathur, V. Balaram, M. Satyanarayanan, S.S. Sawant and S.L. Ramesh, Environ. Earth Sci. 62 , 1085 (2011).

7. V. Balaram and T.G. Rao, At. Spectrosc. 24(6), 206 (2003).

8. J.L.F. Fernández, J.F. Llorens, F.L. López, C.G. Gómez, I. Morell, and D. Gimeno, Fresenius J. Anal. Chem. 368, 601 (2000). 


\section{Atomic Spectroscopy \\ $\bigcup$ Vol. 33(2), March/April 2012}

TABLE VIII

Analytical Data of Trace Elements $(\mathrm{ng} / \mathrm{mL})$ in Surface and Groundwater Samples

(Bore Wells and Open Wells) From Madawara Igneous Complex Uttar Pradesh, India, Determined by ICP-MS With ${ }^{129} \mathrm{Xe}$ as the Internal Standard

\begin{tabular}{|c|c|c|c|c|c|c|c|c|c|c|c|c|c|c|c|c|c|}
\hline \multicolumn{3}{|c|}{$\begin{array}{r}\text { Sample Depth } \\
\text { (in feet) }\end{array}$} & \multirow{2}{*}{$\begin{array}{c}\mathrm{Cr} \\
81.2\end{array}$} & \multirow{2}{*}{$\begin{array}{c}\mathrm{Ni} \\
16.5\end{array}$} & \multirow{2}{*}{$\begin{array}{c}\text { Co } \\
0.28\end{array}$} & \multirow{2}{*}{$\begin{array}{c}\text { As } \\
1.30\end{array}$} & \multirow{2}{*}{$\begin{array}{c}\mathrm{Se} \\
3.20\end{array}$} & \multirow{2}{*}{$\begin{array}{c}\mathrm{Rb} \\
2.32\end{array}$} & \multirow{2}{*}{$\begin{array}{c}\begin{array}{c}\mathrm{Sr} \\
(\mathrm{ng}\end{array} \\
584.4\end{array}$} & \multirow{2}{*}{$\begin{array}{r}\text { Mo } \\
/ \mathrm{mL})\end{array}$} & \multirow{2}{*}{$\begin{array}{c}\text { Ag } \\
0.05\end{array}$} & \multirow{2}{*}{$\begin{array}{c}\text { Cd } \\
0.27\end{array}$} & \multirow{2}{*}{$\begin{array}{c}\mathrm{Sb} \\
0.18\end{array}$} & \multirow{2}{*}{$\begin{array}{c}\mathrm{Ba} \\
45.0\end{array}$} & \multirow{2}{*}{$\begin{array}{c}\mathrm{Tl} \\
0.09\end{array}$} & \multirow{2}{*}{$\begin{array}{c}\mathrm{Pb} \\
1.05\end{array}$} & \multirow{2}{*}{$\begin{array}{c}\mathrm{U} \\
2.08\end{array}$} \\
\hline M1 & 85 & 9.2 & & & & & & & & & & & & & & & \\
\hline M2 & & 8.0 & 74.8 & 19.9 & 0.23 & 1.23 & 4.05 & 1.95 & 262.5 & 1.77 & 0.03 & 0.42 & 0.14 & 47.3 & 0.07 & 0.81 & 1.25 \\
\hline M3 & 180 & 9.2 & 71.3 & 26.8 & 0.23 & .59 & 3.06 & 1.99 & 179.8 & 1.23 & 0.02 & 0.22 & 0.07 & 53.9 & 0.08 & 1.03 & 1.13 \\
\hline M4 & 130 & 6.4 & 1.6 & 61.9 & 0.90 & 1.65 & 2.26 & 1.21 & 133.3 & 1.00 & 0.02 & 0.23 & 0.06 & 38.4 & 0.07 & 0.55 & 0.55 \\
\hline M5 & & 10 & 78.3 & 49.4 & 1.46 & 1.54 & 2.15 & 2.00 & & 0. & & & & & & 46 & 0.49 \\
\hline M6 & & 10.2 & 79.2 & 43.2 & 0.41 & 13.80 & 22.30 & 14.50 & & 0.74 & 0.02 & & & 66.0 & & .96 & 1.22 \\
\hline M7 & 100 & 19.1 & 77.8 & 13.0 & 0.24 & 1.19 & 3.41 & 1.25 & & & & & & & & .46 & 4.38 \\
\hline $\mathrm{M}^{\mathrm{a}}$ & 0 & & 77.0 & 7.6 & & 1.98 & 3.36 & 0.87 & 400.7 & 0.82 & & & & 0.9 & & 0.53 & 2.08 \\
\hline M9 $9^{b}$ & 30 & 14.3 & 83.4 & 10.5 & 0.19 & 1.10 & 1.54 & 1.10 & 326.3 & 0.72 & 0.02 & 0.12 & 0.13 & 64.3 & 0.06 & 0.48 & 1.81 \\
\hline M10 & 100 & 17.5 & 1.6 & 5.6 & 0.18 & 1.15 & 1.83 & 0.58 & 176.3 & 0.73 & 0.02 & 0.17 & 0.04 & 49.0 & 0.06 & 0.47 & 0.68 \\
\hline M11 & 65 & 12.6 & 77.2 & 6.1 & 0.25 & 0.90 & 3.50 & 1.65 & 434.7 & 0.97 & 0.02 & 0.14 & 0.13 & 115 & 0.05 & 0.56 & 1.81 \\
\hline M12 & 90 & 13.7 & 12.3 & 6.0 & 0.44 & 0.60 & 5.80 & 0.68 & 402.9 & 0.80 & 0.02 & 0.01 & 0.03 & 125.8 & 0.03 & 0.01 & 0.71 \\
\hline M13 & 95 & 14.2 & 74.6 & 9.0 & 0.19 & 0.82 & 1.96 & 1.03 & 220.0 & 0.85 & 0.02 & 0.12 & 0.06 & 57.3 & 0.05 & 0.56 & 0.53 \\
\hline $\mathrm{M} 14^{\mathrm{b}}$ & 40 & 17.7 & 81.2 & 8.2 & 0.25 & 0.99 & 2.87 & 1.17 & 438.2 & 0.83 & 0.01 & 0.18 & 0.06 & 85.3 & 0.05 & 3.08 & 0.96 \\
\hline M15 & 100 & 12.3 & 83.6 & 8.3 & 0.24 & 0.88 & 2.97 & 2.55 & 366.0 & 1.05 & 0.02 & 0.16 & 0.07 & 11 & 0.06 & 0.73 & 1.40 \\
\hline M16 & 100 & 17.7 & 75.7 & 7.8 & 0.26 & 0.79 & 1.86 & 4.43 & 423.7 & 0.90 & 0.01 & 0.20 & 0.05 & 265.1 & 0.07 & 0.86 & 1.93 \\
\hline M17 & 150 & 18.0 & 70.3 & 4.9 & 0.25 & 0.82 & 5.25 & 0.98 & 319.2 & 1.16 & 0.02 & 0.12 & 0.06 & 93.3 & 0.06 & 1.10 & 3.10 \\
\hline $\mathrm{M} 18^{\mathrm{b}}$ & 35 & 8.6 & 70.0 & 3.3 & 0.14 & 0.79 & 3.46 & 0.51 & 171.1 & 0.46 & 0.01 & 0.13 & 0.06 & 49.8 & 0.03 & 0.82 & 0.69 \\
\hline M19 & 20 & 29.1 & 72.5 & 4.9 & 0.35 & 1.10 & 3.09 & 1.02 & 332.8 & 0.54 & & & & 87.2 & 0.05 & 1.44 & 0.79 \\
\hline M20 & 110 & 21.8 & 82.6 & 8.9 & 0.18 & 1.48 & 2.99 & 1.72 & 206.4 & 0.83 & 0.01 & 0.17 & 0.10 & 19.4 & 0.05 & 0.71 & $0 ., 63$ \\
\hline
\end{tabular}

${ }^{\mathrm{a}}=$ Surface water. $\quad \mathrm{b}^{\mathrm{b}}=$ Open well.

9. F.D. Ridder, R. Pintelon, J. Schoukens, J. Navez, and L. Andre Dehairs, J. Anal. At. Spectrom. 17, 1461 (2002).

10. F. Vanhaecke, G.D. Wannemacker, L. Moens, R. Dams, C. Latkoczy, T. Prohaska, and G. Stingeder, J. Anal. At. Spectrom. 13, No. 6, 567 (1998).

11. V. Balaram and V.K. Saxena, Proc. First International Conference on Plasma Source Mass Spectrometry, Durham, University, Durham, UK, pg. 44 (1988).

12. F.M. Pearce, Environ. Geochem. Health 13, No. 2, 50 (1991).

13. V. Balaram, Res. J. of Chem. and Environ. 6(2), 67 (2002).

14. A.W. Bott, Curr. Sep. 14, No.1, 24 (1995).

TABLE IX

Results on PGE Recoveries Using ${ }^{129} \mathrm{Xe}$ as the Internal Standard

\begin{tabular}{cccccc}
\hline Sample ID & $\begin{array}{c}\text { PGE Conc. } \\
(\mathrm{ng} / \mathrm{mL})\end{array}$ & \multicolumn{4}{c}{ Recovery of $\mathrm{Rh}, \mathrm{Pd}, \mathrm{Pt}, \mathrm{Au}$ Concentrations } \\
& & $\begin{array}{c}\text { After Pretreatment With Cation Exchange Resin } \\
\mathrm{Rh}\end{array}$ & $\mathrm{Pd}$ & $\mathrm{Pt}$ & $\mathrm{Au}$ \\
\hline Sample 1 & 50 & 49.7 & 49.3 & 47.8 & 47.2 \\
Sample 2 & 100 & 93.7 & 96.7 & 87.6 & 83.5 \\
Sample 3 & 200 & 188.0 & 201.6 & 173.0 & 165.0 \\
\hline
\end{tabular}

15. V. Balaram, R. Mathur, V.K. Banakar, J.R. Hein, C.R.M. Rao, T.G. Rao, and B. Dasaram, Indian J. Marine Sciences 35, No.1, 7 (2006).

16. C.T. Kamala, V. Balaram, M. Satyanarayanan and K.V.S. Subramanyam, J. Appl. Geochem. (2012) (in press).
17. V. Balaram, J. Geol. Soc. India 72 , 661 (2008).

18. T.W. May and R.H. Wiedmeyer, At. Spectrosc. 19, No. 5, 150 (1998). 